Article

\title{
Spatiotemporal Patterns and Socioeconomic Contexts of Vegetative Cover in Altamira City, Brazil
}

\author{
Scott Hetrick $^{1, *}$, Rinku Roy Chowdhury ${ }^{1,2}$, Eduardo Brondizio ${ }^{1,3}$ and Emilio Moran ${ }^{1,3,4}$
}

1 Anthropological Center for Training and Research on Global Environmental Change, Indiana University, Student Building 331, 701 E. Kirkwood Avenue, Bloomington, IN 47405, USA; E-Mails: rroychow@indiana.edu (R.R.C.); ebrondiz@indiana.edu (E.B.); moran@indiana.edu (E.M.)

2 Department of Geography, Indiana University, Student Building 120, 701 E. Kirkwood Avenue, Bloomington, IN 47405, USA

3 Department of Anthropology, Indiana University, Student Building 130, 701 E. Kirkwood Avenue, Bloomington, IN 47405, USA

4 Center for Global Change and Earth Observations and Department of Geography, Michigan State University, Manly Miles Building 218, 1405 S. Harrison Road, East Lansing, MI 48823, USA

* Author to whom correspondence should be addressed; E-Mail: shetrick@indiana.edu; Tel.: +1-812-856-6813; Fax: +1-812-855-3000.

Received: 25 September 2013; in revised form: 27 November 2013 / Accepted: 2 December 2013 / Published: 12 December 2013

\begin{abstract}
Ecosystem services provided by urban vegetation can ameliorate problems common to urban environments while improving the quality of life of urban residents. Much research in urban ecology has analyzed urban environmental dynamics in the global north; rapidly urbanizing areas in the global south have not received commensurate attention. The land cover dynamics of mid-sized cities in the global south remain under-explored in particular. In this article, we investigate the spatial patterns and socioeconomic contexts of urban vegetation in Altamira, Brazil, a mid-sized but rapidly expanding city in the Amazon. Using time series remotely sensed imagery, we profile changes in urban land cover, and link them to socioeconomic indicators at the census sector (tract) level. While studies of urban environmental justice in the global north largely report that greener urban landscapes prevail in affluent neighborhoods, our analysis reveals significantly lower vegetative cover in higher-income sectors of Altamira. Vegetative cover is also significantly lower in sectors with higher housing density, time since urbanization and better infrastructure, and appears linked to housing tenure. Studies of
\end{abstract}


vegetative outcomes in similar urban environments should investigate socioeconomic and demographic contexts while also integrating recent infrastructure development and density-dependent growth patterns.

Keywords: land change science; urbanization; urban ecology; vegetative cover; spatio-temporal analysis; Brazil

\section{Introduction}

Urbanization processes have dramatic impacts on environmental change globally, driving transformations to local and regional land cover, hydrologic regimes and nutrient flows [1-6]. While studies of land-use and-cover change (LUCC) have often focused on rural areas, research is increasingly turning to ecological and land cover dynamics within cities, with attention to vegetative cover therein. In particular, rapidly urbanizing areas in the global south represent an increasingly larger share of world population, yet limited attention has been paid to land cover dynamics in such areas [7]. Studies of urban vegetation change have direct implications for planning and public policy. The ecosystem services and social benefits that urban vegetation provides have the potential to ameliorate many of the problems common to urban environments and to improve the quality of life of urban residents [8-10]. Conversely, inequitable access to these services may lead to environmental injustice [11]. As the world continues to urbanize, there is a pressing need to analyze emerging patterns of urban vegetative cover and understand their social contexts, including potential environmental inequities. Methodological developments are needed to spatially and temporally connect extant land cover and socioeconomic variables to reveal the patterns, trajectories and drivers of urban vegetative change. Such research is beginning to emerge for urban areas in the global north [11-13] but remains lacking for the global south.

In this research, we address the aforementioned gaps in an expanding, medium-sized city in the state of Pará in Brazil, an example of an urbanizing tropical frontier environment. The main objectives of this research are to: (1) characterize the spatial distribution of urban vegetation in Altamira City; (2) document the spatiotemporal trajectories of urban expansion; and (3) analyze the key social indicators associated with vegetation distribution, including a consideration of equity. We address these research objectives by integrating high resolution, space-based imagery from 2008 with multi-platform time series data to map urban expansion and recent land cover, and by linking extant cover to socioeconomic variables at the census sector (tract) scale using multivariate statistical analyses.

\subsection{Urbanization and Global Land Use Cover Change}

Urban land use and its expansion pose significant environmental challenges. Infrastructure development, energy requirements, shifting transportation patterns, and the impacts of urban expansion on food and water security all reflect the increasing scope of urbanization and its implications for environmental change on local, regional and global scales. The conversion of natural ecosystems and 
agricultural lands to built urban environments has large impacts on regional ecology and earth system functioning [1-6].

Urban areas are estimated to produce more than three quarters of global greenhouse gas emission [2], and play increasingly important roles in altering global biogeochemical cycles [1], in habitat fragmentation and biodiversity impacts [6] and in the introduction and spread of exotic species [2]. The ecological footprints of cities reach well beyond urban boundaries [3-5], progressively affecting peri-urban regions as they become enmeshed with urban economies [7]. With urban areas expanding globally, it is necessary to examine both urban and peri-urban land conversions [14-16] in focused urban research for the proper planning and management of cities [7,14-18]. Of particular interest to this research, the international research community has called for more study of urbanization in tropical and semi-tropical areas [7], stressing the importance of considering ecosystem services in urban planning and design as a way to promote more sustainable urban forms [7,19-24].

The characteristics of urban and peri-urban LUCC should be understood within broader socioeconomic and environmental processes [25]. Population pressure and migration, economic growth, as well as historical, institutional and policy factors are significant drivers of urbanization and social stratification within cities. While an estimated 3.7 billion people now live in urban areas, that figure is expected to grow to almost 5 billion by 2030 [26,27]. Urbanization has also resulted in a dramatic rise in the number and size of large cities, with commensurate attention by academia and the popular press. However, smaller cities with 500,000 or fewer inhabitants are in fact the fastest growing urban areas worldwide, and will continue to account for about half the urban population in the foreseeable future [26]. Such smaller cities, especially those in the developing south, are also the least equipped to manage the environmental and social challenges associated with rapid urbanization [28,29], yet they are understudied relative to their larger counterparts. In particular, urban poverty in Latin America is a significant, persistent problem due to the rapid process of urbanization and lingering regional poverty and income inequality [30-32]. It is important to understand how the spatial locations of environmental amenities, such as urban vegetation, align vis-à-vis patterns of urban poverty and affluence in Latin America, among other regions.

\subsection{The Ecological and Social Contexts of Urban Vegetation}

Urban vegetation provides a variety of well-documented ecosystem services including carbon sequestration [33], urban climate moderation [34], the reduction of air and noise pollution [35,36], flood control [37], and the enhancement of urban wildlife habitats [38], among others [11,39,40]. Urban vegetation also positively contributes to sense of safety [41], reduced incidence of domestic violence [42], and several aspects of human physical and mental health [9,10,43-46]. Thus, urban vegetation has the potential to mitigate many of the problems common to urban environments, improving city dwellers' quality of life.

Given the benefits associated with urban vegetation, understanding the social processes that generate vegetative cover in cities is important for both scientific research and policy. Several studies have integrated socioeconomic data into studies of urban LUCC, ecology and political ecology. Population density [47] and processes of social stratification [48] have been found to drive vegetation distribution in urban ecosystems through plant and animal displacement by built environments, as well 
as via altered power relations [13,49]. Income and land or housing tenure may vary across neighborhoods, with consequences for land use decisions and vegetative cover. The relative influence that different neighborhoods have in urban political processes can also lead to inequitable distribution of green investments within the city $[12,48]$. Accordingly, research in the linked fields of urban political ecology and environmental justice has analyzed how the social production of urban environments can lead to an uneven distribution of environmental goods and services, including that of vegetative cover [11]. By investigating factors such as socio-economic class, racial identity, ethnicity and property ownership and tenure, these fields are contributing important insights into the social formation of urban environments and associated environmental inequities [11,13,50].

In Brazil, the Legal Brazilian Amazon (LBA) contains the world's largest rainforest, but is also an area of rapid urbanization. Over the past four decades, the federal government of Brazil has encouraged the occupation of the Amazon through a series of colonization projects, resource extraction, and economic development. Consequently, urbanization occurred due to a rural outmigration within the Amazon region as well as urban frontier migration from outside the region. By the early 1990's most of the region's population lived in urban rather than rural areas, though rural-urban connections are strong [51,52]. Today over $70 \%$ of the LBA population lives in urban areas [53]. Despite the prominence of urban areas in the region, human-environment research in the Amazon has mainly focused on rural contexts [53].

The case study reported here addresses this gap by focusing on Altamira, a rapidly expanding frontier city in the Brazilian Amazon. In so doing, it contributes to urbanization and land change science research on the expansion of mid-sized cities and on the socioeconomic contexts of their urban vegetation patterns. While our findings may not apply to all cities, our study sheds important light on relatively young, mid-sized cities of the developing south, an important sector among cities worldwide, and on the case of urbanization of the Amazon in particular. The following sections detail our study area, methods, and results pertaining to the main trajectories of urban expansion in Altamira, and the relationship of its vegetative cover patterns to the local socioeconomic context.

\section{Materials and Methods}

\subsection{Study Area}

Located in the Xingu River basin, the city of Altamira is a key node found on the Transamazon Highway (BR-230) where it crosses the Xingu River in central Pará state, Brazil (see Figure 1). Jesuit missionaries first established the Altamira settlement in the 18th century as a mission to protect indigenous populations from Portuguese enslavement. Altamira experienced rapid growth during the rubber boom era between 1880 and 1925, during which it acted as regional trading post. Population and urban development boomed in the early 1970s as the city became a central focus of Amazon occupation through the "Altamira Integrated Colonization Project". Population increase has been linked to migration from regions all over Brazil driven by the National Institute for Colonization and Agrarian Reform in Brazil (INCRA) development plans, and more recently, by regional rural to urban migration. Today Altamira City acts a service center for an expansive agricultural region dominated by pasture, small scale farming, and agro-forestry systems, in particular cacao [54]. Altamira is the 
epicenter of the contested Belo Monte dam project, which will further impact urbanization in the region. According to the Brazilian census (Instituto Brasileiro de Geografia e Estatística-IBGE), Altamira municipality's urban population expanded from 62,285 residents in 2000 [55] to 84,092 in 2010 [56]. The current total population in Altamira municipality is estimated at 105,106 [57], although informal estimates of Altamira's population (urban and peri-urban areas) by local policy makers and long-time residents range as high as 140,000 [58].

Figure 1. Location of Altamira City, Pará State, Brazil, and census sectors within. Census sectors in red represent sectors of primarily urban character and are the focus of this research. The 2008 QuickBird image is displayed in true color composite, bands 3, 2, 1 (RGB).

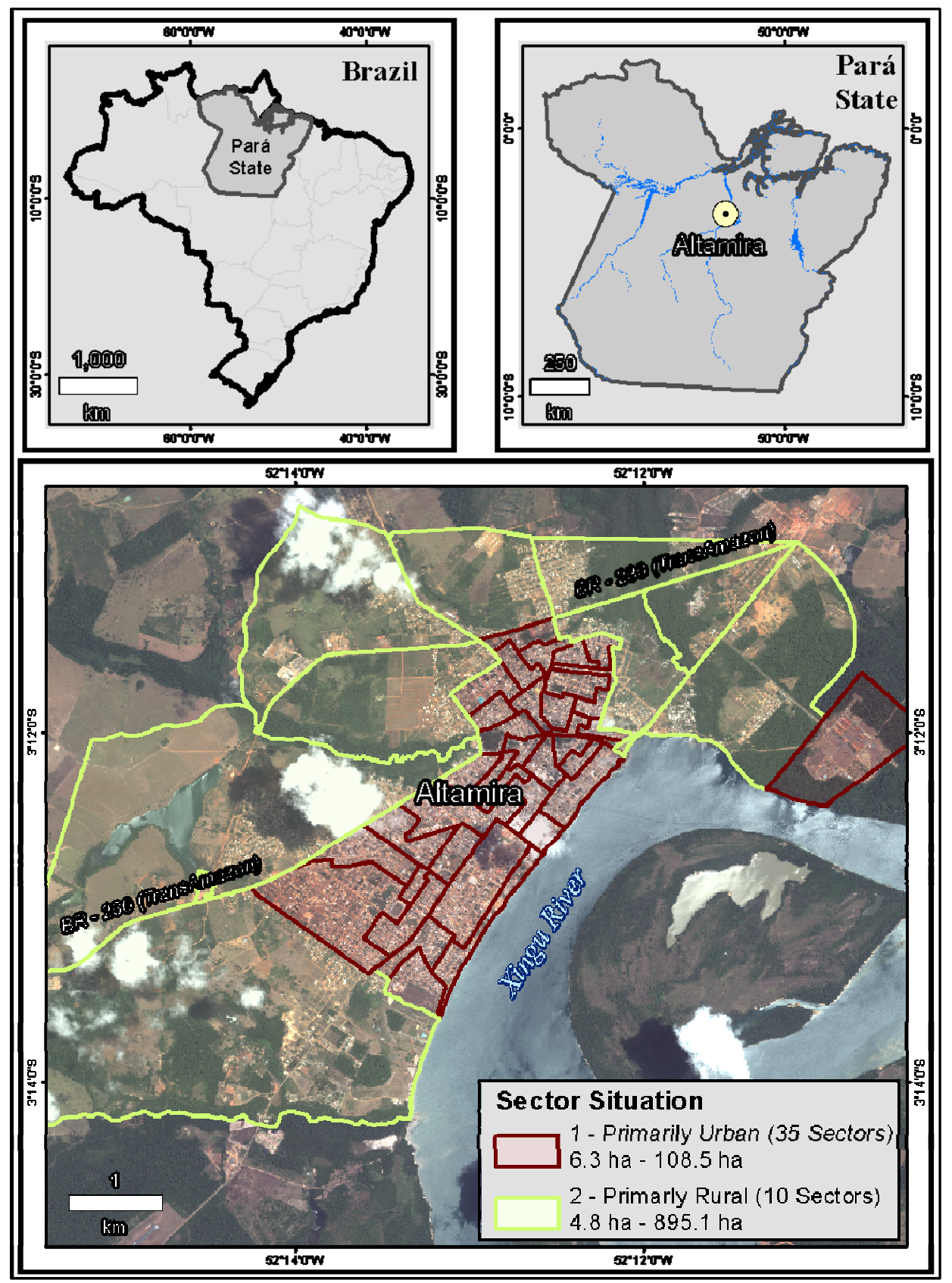

This research investigates 45 census sectors (approximately equivalent to US census tracts) delimited by IBGE as the city of Altamira, based on the Brazilian census of 2000. Census sectors, as 
defined by IBGE, are the minimum areal units created for the purpose of cadastral control of data collection. Beyond the parameters of size, they take into consideration political-administrational divisions, the legal framework and rural versus urban areas [55]. IBGE codes census sectors according to their dominant urban or rural character. This research will focus on the "situation 1" census sectors or those that IBGE defines as urban, based on their extent of impervious surface and intense human occupation (see Figure 1).

\subsection{Data Collection and Preprocessing}

Data sets employed for this research include a variety of time series remotely sensed (RS) imagery and year 2000 census data (Table 1). Despite the eight-year difference between the year 2000 census and 2008 QuickBird derived land cover data employed, we feel the comparison is valid due to a potential temporal lag between socioeconomic dynamics and related changes in vegetative cover. In addition, between 2000 and 2008 urban growth in Altamira was moderate, a situation that changed dramatically thereafter with the initial onset of the Belo Monte hydroelectric dam project. The diverse aerial and satellite image data were coregistered and subset to the study area, and used to digitize the urban expansion of Altamira over time. The 2008 QuickBird image was utilized to calculate Normalized Difference Vegetation Index (NDVI) values for a quantitative (continuous) characterization of vegetative cover, and to create a land cover classification.

QuickBird collects panchromatic imagery at $0.6 \mathrm{~m}$ resolution and multispectral imagery at $2.4 \mathrm{~m}$ resolution. To take full advantage of the multi-spectral reflection data and high resolution panchromatic band, data fusion was performed using a high pass filter resolution merge algorithm, generating an output with a high level of detail and a realistic representation of original multispectral scene colors [59]. The resulting imagery is multispectral with improved spatial resolution. The QuickBird imagery was resampled to $1 \mathrm{~m}$ during the data fusion process.

Polygon shapefiles of the year 2000 census sectors were acquired from IBGE and co-registered to the 2008 QuickBird image. Altamira is composed of 45 census sectors based on the 2000 Brazilian census, 35 of which are noted as primarily urban in character. Census socioeconomic variables corresponding to the 2000 sectors were also acquired, cleaned and linked to the vector data to enable variable mapping and spatial analysis over the study area. All spatial data were projected to the Universal Transverse Mercator (UTM) coordinate system, Zone 22, South American Datum (Brazil). All socioeconomic data and derived land cover variables were aggregated to the scale of the census sector.

\subsection{Vegetation Characterization, Urban Expansion and Statistical Analysis}

To map vegetative cover and its expansion and explore the relationship between urban vegetation and socioeconomic variables in Altamira, a variety of spatial and statistical analyses were performed on the datasets described above. The primary software packages utilized were ArcGIS 10.0, ERDAS IMAGINE 2010 and PASW Statistics 18.

The 2008 QuickBird image was classified using segmentation-based classification, a technique which can improve classification accuracy in high resolution images [60]. Image segmentation partitions raster data into homogenous regions, based on pixel values and locations. Individual 
segments are composed of grouped pixels having similar spectral signatures and spatial connectivity. The mean spectral value for each band of the original multi-spectral image was extracted and assigned to each respective segment, thereby reducing the high within class spectral variation found in the raw per-pixel image, making land cover classification more efficient and accurate. The multi-spectral segmentation image was classified using a supervised, maximum likelihood algorithm. Training samples were composed of a combination of ground truth data collected by collaborating researcher Tony Cak during fieldwork in 2008-2009 and image interpretation of the 2008 QuickBird image.

Table 1. Data utilized and derived datasets.

\begin{tabular}{|c|c|c|c|c|}
\hline Remotely Sensed Data & & & & \\
\hline Sensor/Platform & Date & $\begin{array}{c}\text { Spatial } \\
\text { Resolution }\end{array}$ & $\begin{array}{c}\text { Spectral } \\
\text { Resolution }\end{array}$ & Derived Datasets \\
\hline QuickBird & 2008 & $1 \mathrm{~m}$ & Visible, NIR & $\begin{array}{l}\text { NDVI, Land Cover } \\
\text { Classification, Urban Trajectory }\end{array}$ \\
\hline IKONOS & 2000 & $1 \mathrm{~m}$ & Visible, NIR & Urban Trajectory \\
\hline Landsat TM \& ETM+ & $\begin{array}{c}1985,1991, \\
1996,2000,2008\end{array}$ & $30 \mathrm{~m}$ & $\begin{array}{l}\text { Visible, VNIR, } \\
\text { SWIR, LWIR }\end{array}$ & Urban Trajectory \\
\hline Aerial Photo & 1970 & $4 \mathrm{~m}$ & $\mathrm{~B} \& \mathrm{~W}$ & Urban Trajectory \\
\hline \multicolumn{5}{|l|}{ Vector/Tabular Data } \\
\hline Dataset & Date & Scale & & Derived Datasets \\
\hline IBGE Census Data & 2000 & $\begin{array}{l}\text { Aggregated to } \\
\text { Census Tract }\end{array}$ & & Independent Variables \\
\hline IBGE Census Tract Shapefile & 2000 & Census Tract & & Spatial Unit of Analysis \\
\hline ACT Ground Truthing Data & 2008 & $\mathrm{~N} / \mathrm{A}$ & & Land Cover Classification \\
\hline
\end{tabular}

For this research, the main goal of the classification was to isolate and quantify the spatial extent of vegetative cover per census sector, our target dependent variable. Initially, land cover signatures were extracted for all land cover classes identified in the study area, including high and low albedo impervious surfaces, forest canopy, shrub canopy, urban grass and pasture, several classes of bare soil and water, burn scars, and vegetative versus urban shadows. The final result contained five aggregated land cover classes: Tree canopy and shrubs; Herbaceous cover; Wetlands; Water, and an aggregate class comprised of Impervious surface (IS), bare soil (BS) and burn scars (Burn). The classification was reviewed and some areas, such as areas with cloud or cloud shadow cover were further edited using visual interpretation and manual digitizing (see Figure 2).

Accuracy assessment of the 2008 land cover classification was conducted using the error matrix approach [61] (Table 2). To ensure that each land cover type was sufficiently represented we randomly assigned 300 test sample points to the classified image, stratifying the sample so that each cover class was represented with at least 50 points. Reference values, assigned to each sample through interpretation of the raw 2008 image were compared to the actual class value results of the corresponding classified image. As Table 2 shows, the overall classification and each land cover class achieved high levels of accuracy. Following this, we derived the total and proportional extents of the vegetative cover in each census sector, thus generating the dependent variables for our analysis. 
Figure 2. 2008 Land cover in Altamira based on QuickBird classification. IS/BS/Burn = Impervious surface, bare soil and burn scars. Absolute areas in hectares and respective percentages listed. Total study area $=1,643$ ha.

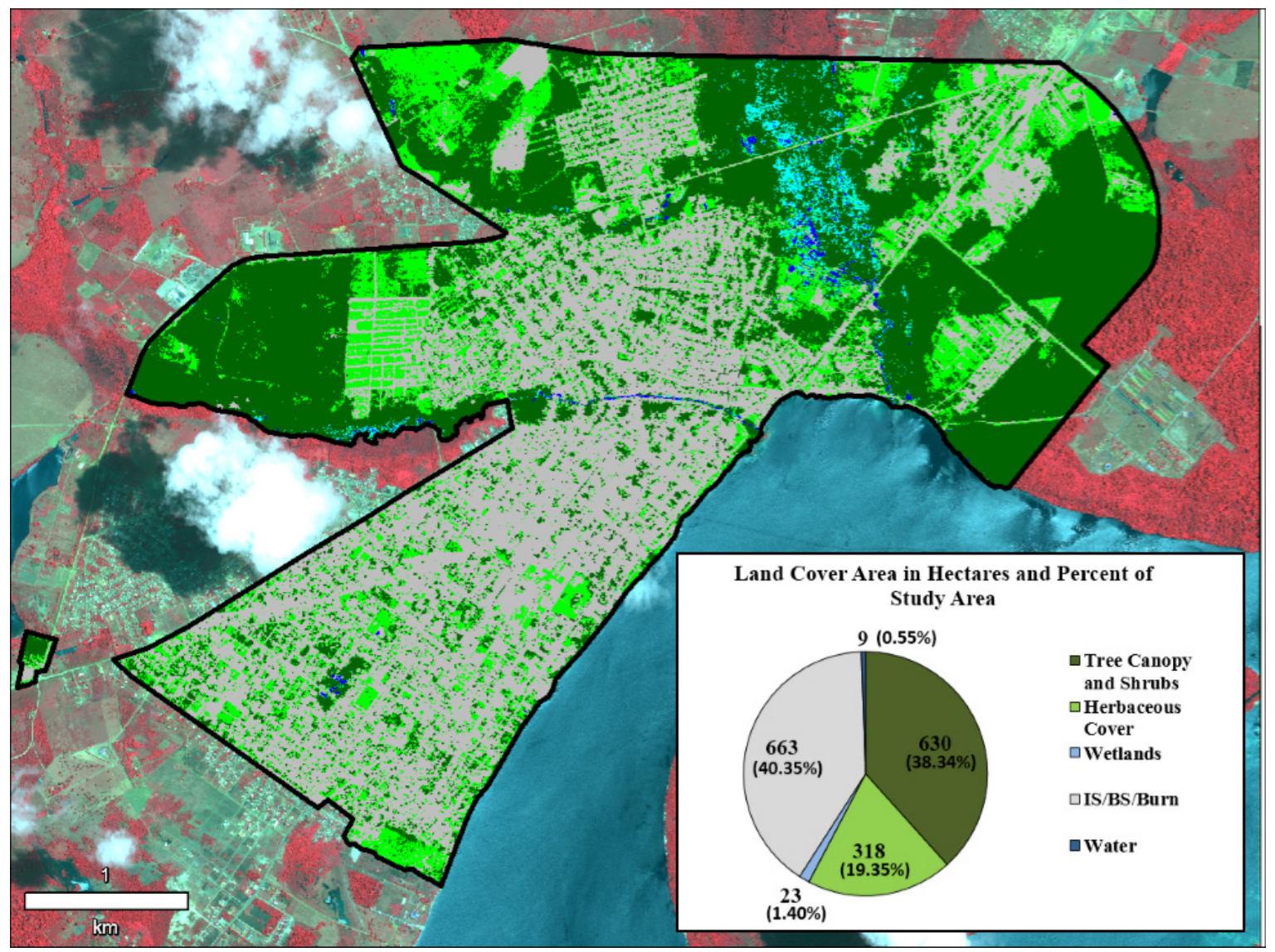

Table 2. Accuracy Assessment of 2008 QuickBird Classification.

\begin{tabular}{cccc}
\hline Class Name & Producers Accuracy & Users Accuracy & Kappa Statistic \\
\hline Tree Canopy & $92.00 \%$ & $100.00 \%$ & 1.0000 \\
Herbaceous Cover & $94.74 \%$ & $90.00 \%$ & 0.8765 \\
Wetland & $94.12 \%$ & $96.00 \%$ & 0.9518 \\
IS/BS/Burn & $93.15 \%$ & $95.77 \%$ & 0.9442 \\
Water & $100.00 \%$ & $88.00 \%$ & 0.8594 \\
\hline
\end{tabular}

Overall Classification Accuracy $=94.33 \%$; Overall Kappa Statistics $=0.9286$.

To include a temporal dimension our study of Altamira's urban vegetative patterns, we constructed a profile of urban expansion over time using the times series of aerial photos, Landsat, IKONOS and QuickBird imagery. We considered the 2000 sector polygons in conjunction with the time series, to determine the onset (phase) of urbanization for each sector based on earliest appearance of the presence of permanent human made features such as roads, dwelling structures and other indicators of intense human occupation. For the purposes of this research if at least $50 \%$ of a 2000 sector was built/impervious surface at a certain date then it was considered initially urbanized by that date. Urban coverage maps for the year 1970, 1985, 1991, 1996, 2000 and 2008 were created by coregistering the time series RS data and digitizing urban areas (see Figure 3). It should be noted that these years are not based on equal intervals but instead represent variable time steps based on cloud free imagery available 
for analysis. Based simply on the available timeline of remote sensing data, six possible phases of urbanization may be identified. Based on phase of initial sector urbanization, urban phase 1 corresponds to those sectors initially urbanized in or before 1970, urban phase 2 corresponds to those sectors initially urbanized between 1970 and 1985, urban phase 3 corresponds to those sectors initially urbanized between 1985 and 1991, urban phase 4 corresponds to those sectors initially urbanized between 1991 and 1996, urban phase 5 corresponds to those sectors initially urbanized between 1996 and 2000, and phase 6 refers to sectors initially urbanized between 2000 and 2008. Regarding the latter, it is important to point out that all sectors characterized as urban by the 2000 IBGE census were urbanized by 1996 according to our definition. The urban expansion maps were utilized to determine trajectories of urban growth and to test the relationship between initial time of a sector's urbanization and vegetative cover in 2008, filling a temporal gap often found in studies of urban vegetation dynamics.

Figure 3. Urban expansion in Altamira from 1970 to 2008 with cumulative urban areas.

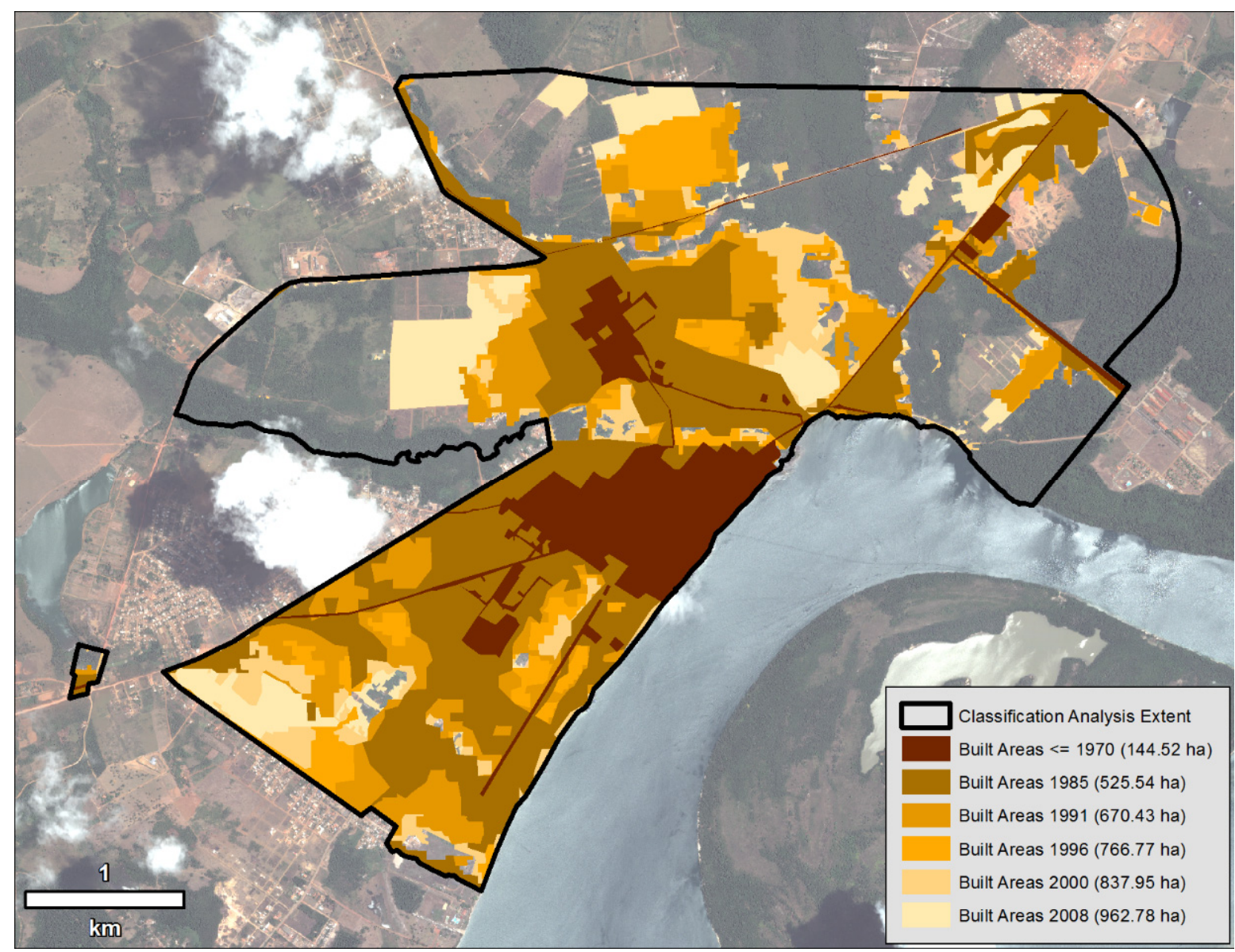

Socioeconomic drivers of urbanization such as demographic, economic, institutional, and technological-infrastructure factors have been emphasized in the urban LUCC literature, and we selected variables to proxy for such drivers based on their availability in the 2000 Brazilian Census. Chosen census variables include demographic data (number of households per hectare), housing tenure (percent sector households owning and percent households renting), infrastructure development (percent sector households connected to Altamira's central water distribution system), and economic 
(mean monthly household income). These were added to the urbanization phase variable described above, to form our set of independent variables. All independent variables were checked for multicollinearity using Pearson's and Spearman's correlation coefficients. Linear regression of dependent and independent variables and subsequent investigation of residual histograms and plots of regression standardized residuals against predicted values revealed that the raw data meets the assumptions of homoscedasticity. Analysis of residuals revealed that one census sector, a military base, is a clear outlier in a number of factors relative to the other 35 urban census sectors. This sector was removed from the study sample. A multivariate regression model was then run to explore the relationships between the dependent variable of percent vegetative cover within each urban sector and the independent variables.

\section{Results}

Our research addresses three main questions about urbanization and vegetative patterns in Altamira: the current distribution of urban vegetation, the spatiotemporal patterns of urban development of the city, and the relationship of urban vegetation to socioeconomic contexts. In the following sections, we describe the results obtained through exploratory statistical analysis as well as a multivariate regression model.

\subsection{Exploratory Statistics}

To address the research questions outlined in the introduction of this paper, we conducted exploratory statistical analyses comparing NDVI values and classified land cover data to socio-economic-demographic indicators and urban expansion over time. Urbanization began at Altamira's core near the Xingu river and rapidly radiated outward (Figure 3), first to the immediate west and north of the core and then building on new neighborhoods as immigration to the city fueled rising demand for housing and infrastructure. We compared census sectors to the urban expansion map to determine times of initial sector urbanization, and classified the sectors according to their urbanization phase (Figure 4). Essentially, this allows us to view the locations and spatial extents of older to younger neighborhoods or sectors in the city. We find that all 34 of the urban sectors meet the $50 \%$ threshold discussed above by 1996 or earlier, essentially yielding four actual, experienced urbanization phases, rather than the six phases that are theoretically possible (see Section 2.3 above). These four urbanization phases are subsequently used as independent variables in the regression analysis to follow.

Comparing the 2008 land cover classification (Figure 2) with urban expansion (Figure 3) within our study area we find that 36 sectors (34 urban and 2 of rural character) were urbanized by 2000, according to our $50 \%$ threshold criteria. The remaining sectors had not reached the $50 \%$ threshold by 2008. We assess the absolute and relative extents in different land cover types within these 36 sectors classified by urbanization phases (Figure 5). Urban area increased rapidly from 1970 to 1985, growing 270 ha or $16.4 \%$ of the study area. In contrast, the following 15 years from 1985 to 2000 saw continued urban expansion (adding 133 ha or $8.1 \%$ of study area), but at a relatively slower pace. We then turned our attention to proportional vegetative cover in particular, to examine older to younger

neighborhoods/sectors according to the extents of canopy cover, herbaceous cover or wetlands present 
therein in 2008 (Figure 6). It is clear that sectors that were initially urbanized early tend to have less percent vegetative cover currently (in 2008), while the most recently urbanized (youngest) sectors have the largest proportional vegetative cover. Thus, vegetation in Altamira shows clear patterns linked to neighborhood or sector age.

Figure 4. Urbanization phase (dates of initial urbanization) of urban census sectors.

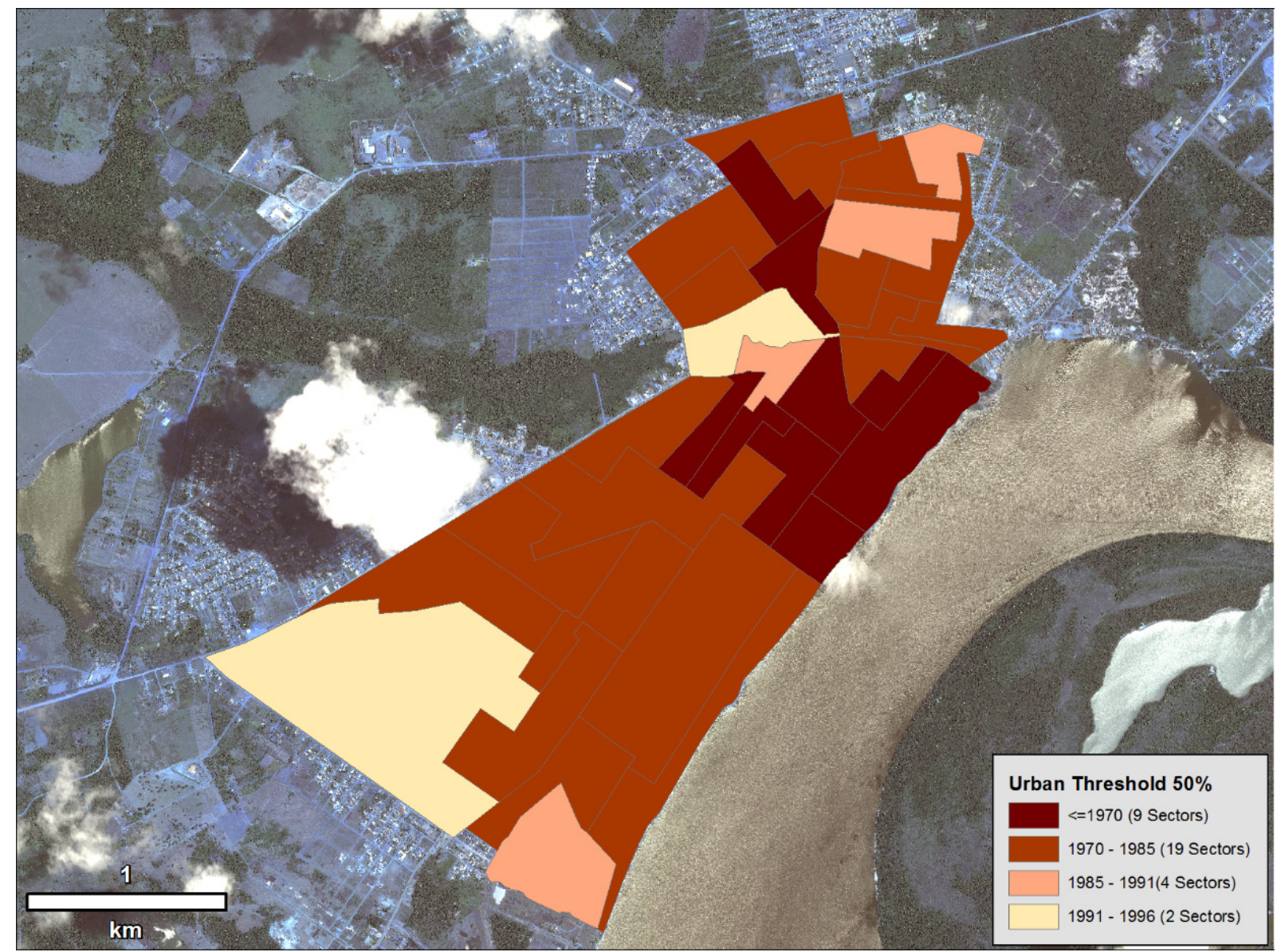

Figure 5. 2008 Land cover distribution in 34 urban and 2 rural sectors, according to urbanization phase.

2008 Land Cover by Time of Urbanization

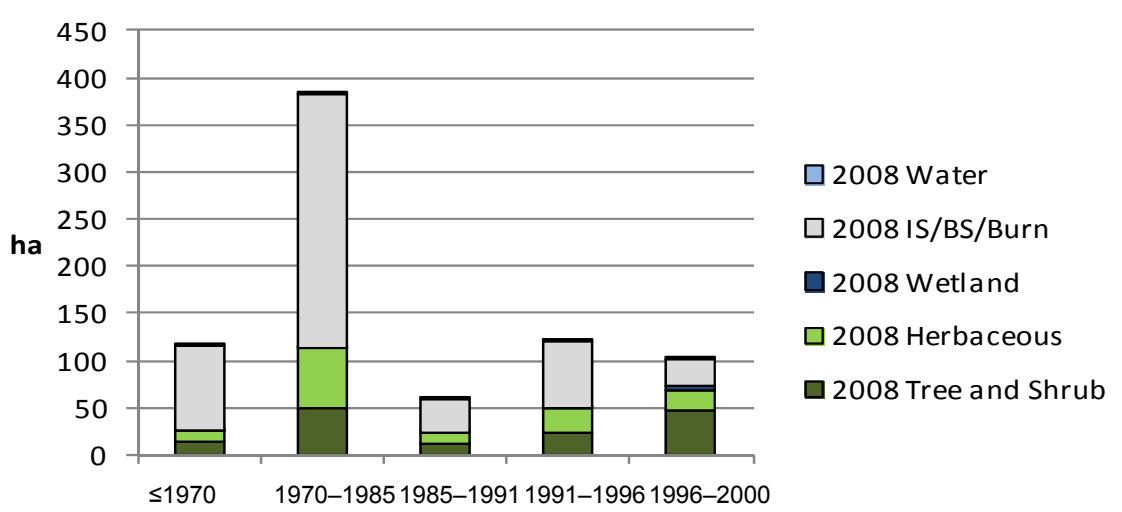


Aside from vegetation-sector age relationships, exploratory analyses of vegetative cover and relative greenness also indicate the importance of social and economic factors. For instance, urban sectors that had higher mean monthly household incomes appear to display lower average values of relative greenness as captured by pixel NDVI values (Figure 7a). Four census sectors with extensive cloud or shadow cover were excluded from the NDVI analysis. Mean household monthly income for the 30 sectors examined ranged from $\mathrm{R} \$ 241$ to $\mathrm{R} \$ 1,198$ ( $1 \mathrm{R} \$ \approx 1.8 \mathrm{USD} \$$ in 2000 ), and corresponded to mean NDVI values of 0.148649 to 0.349969 . This trend is also evident for percent vegetated area of sectors based on the 2008 QuickBird classification (Figure 7b). Age of the urban sector and household income correlate negatively with percentage of vegetation.

Figure 6. Proportion of vegetative cover in 2008, within earliest to most recently urbanized sectors (34 urban, 2 rural).

\section{Percent Vegetative Cover by time of Urbanization}

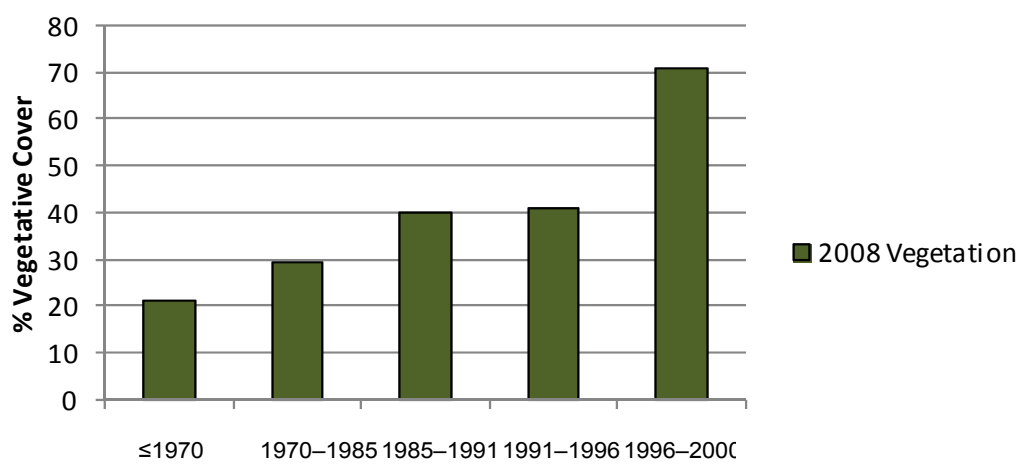

Figure 7. Relationships of sector vegetation to mean monthly household income in $\$ \mathrm{R}$ (four sectors with cloud cover were dropped from the NDVI analysis). (a) Relative greenness by income in sectors $(\mathrm{N}=30) ; \mathrm{R}^{2}=0.413$; (b) Percent vegetated area by income in sectors $(\mathrm{N}=34) ; \mathrm{R}^{2}=0.179$.

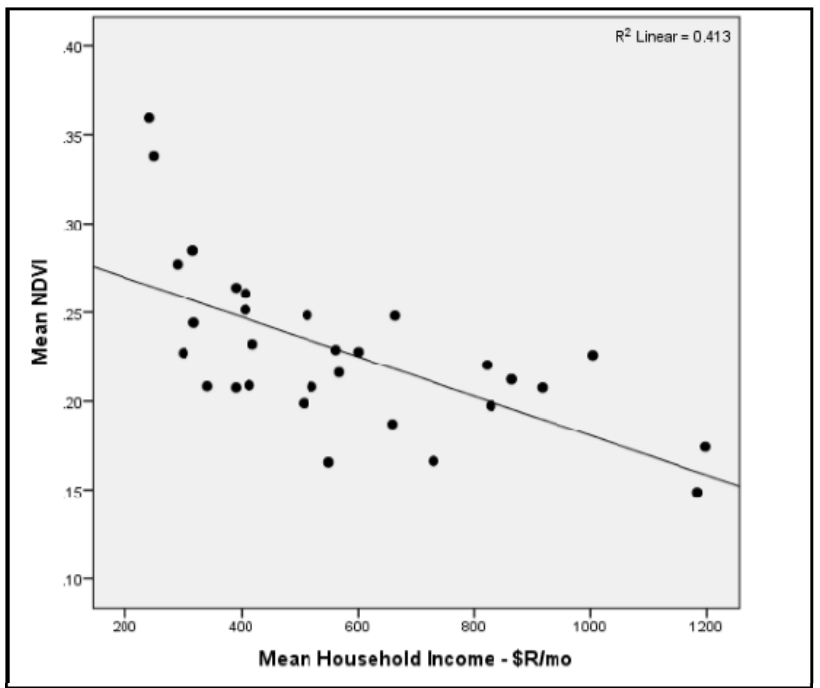

(a)

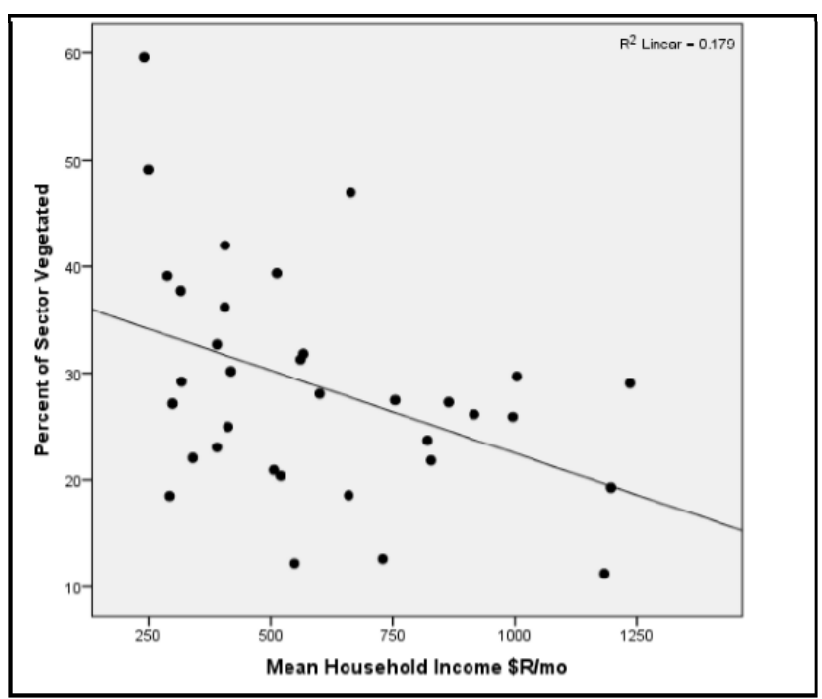

(b) 
We then grouped the 34 urban sectors into three classes based on their average monthly household income (low: R\$ 241 to R \$ 419, medium: $\mathrm{R} \$ 507$ to $\mathrm{R} \$ 755$ and high: $\mathrm{R} \$ 822$ to $\mathrm{R} \$ 1,236$ ), based on a natural breaks (Jenks) classification of income values, and compared the land cover areas of low, medium and high income sectors (Figure 8). Mean NDVI values corresponding to the high income class $=0.198(\mathrm{~N}=7$ sectors $)$, for the medium income class the mean NDVI $=0.209(\mathrm{~N}=10$ sectors $)$, for the low income class the mean NDVI $=0.259(\mathrm{~N}=13$ sectors $)$. Figure 8 demonstrates that low and medium income sectors have slightly larger cumulative areas in tree and shrub cover. On the other hand, grass cover is lowest for the low-income sectors, but relatively similar for medium and high income sectors. Sectors with the highest mean monthly household incomes also have the largest extents of impervious surfaces. Water and wetlands together comprised less than 1 ha for each income category. It is important to note that different patterns may emerge when reporting data at various scales of analysis. We chose to group variables into low, medium and high categories in an attempt to uncover basic patterns within the data. These groupings should be viewed along with the scatterplots provided to better understand data point trends. Distinct categorization approaches may well yield distinct results, commensurate with the modifiable areal unit problem.

Figure 8. Land cover extents in sectors of low, medium and high mean monthly household incomes.

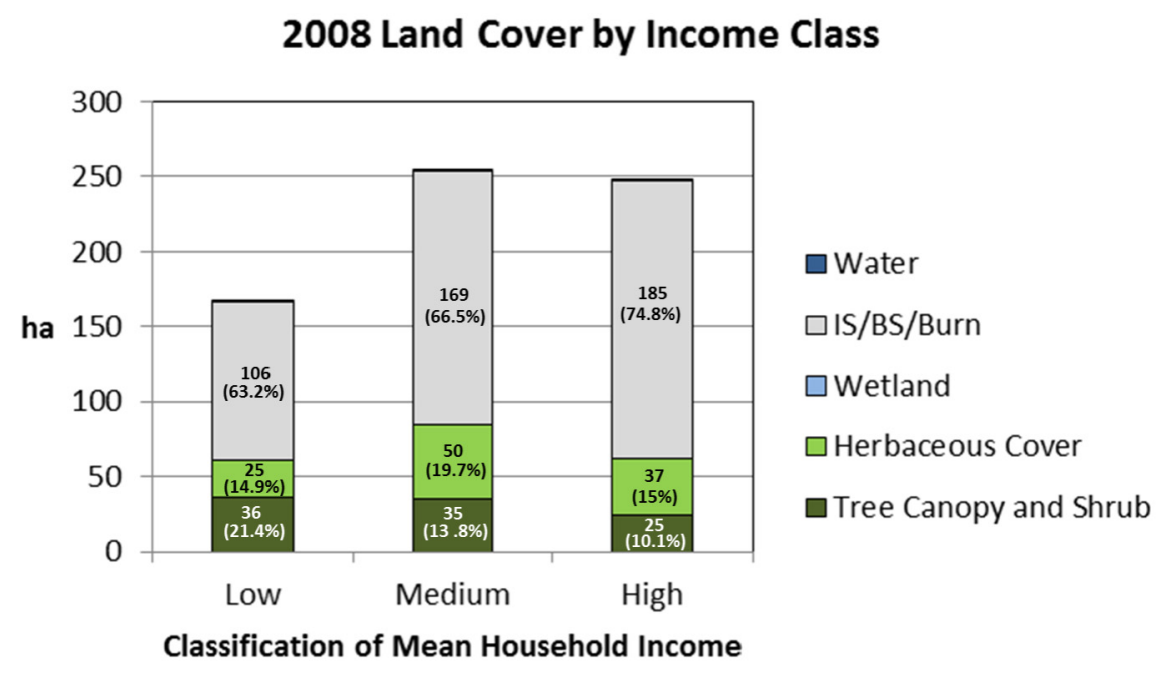

To explore how vegetative cover (Tree Canopy and Shrub, Herbaceous Cover and Wetlands) varied with demographic factors, we calculated household density for each sector based on 2000 sector household counts and sector area. As with the income variable, we derived three classes of sector household density based on a natural breaks classification into high 35-38.5 households/ha $(\mathrm{N}=5)$, medium 19.4-30.6 households/ha $(\mathrm{N}=16)$ and low 5.6-18.8 households/ha $(\mathrm{N}=13)$ levels of household density. As anticipated, we find some evidence indicating that a relatively high household density per hectare corresponds with lower percent vegetative cover (Figure 9a). This is further made evident when viewing percent vegetative cover for sectors grouped in low, medium and high density categories: the lowest household density class had the greatest proportional cover in vegetation, and the high density class had the lowest (Figure 9b). 
In assessing the relationship of vegetative cover to infrastructure connectivity, we utilized the percent of households connected to the city's main water network as a proxy for infrastructure development. Hypothetically, areas showing significant investment in infrastructure development might also invest in urban vegetation for its numerous aesthetic, social and ecosystem amenities. However, we find that in Altamira's urban sectors, higher percent vegetative cover tends to correspond with lower percentages of households connected to the city's main water network (Figure 10).

To review the importance of housing tenure for patterns of vegetation found in Altamira, we examined the percent of households owning residences (paid for or in mortgage) and percent of households renting their residences per census sector. Census sectors with high percentages of home ownership tend to have high vegetative cover (Figure 11a), while sectors with high percentages of households renting tend to have lower vegetative cover (Figure 11b).

Figure 9. Mean vegetative cover and household density. (a) Percent vegetated by household density in sectors $(\mathrm{N}=34) ; \mathrm{R}^{2}=0.107$; (b) Percent vegetated in sectors of low, medium and high household density $(\mathrm{N}=34)$.

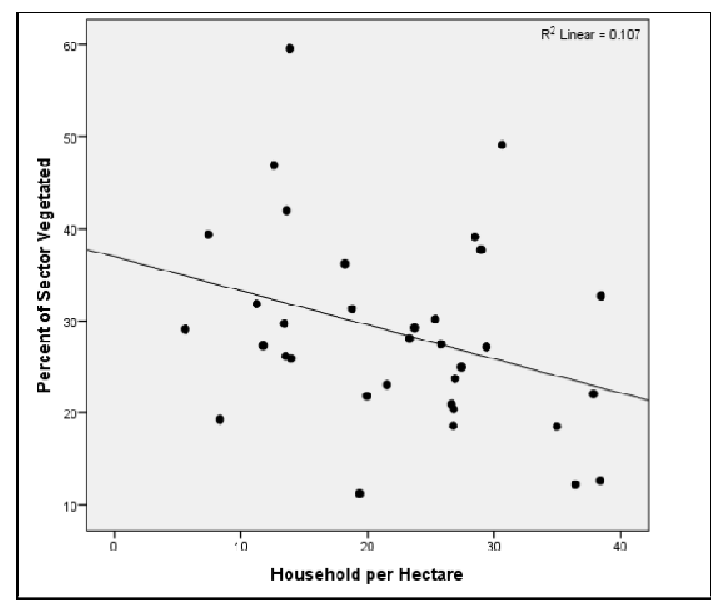

(a)

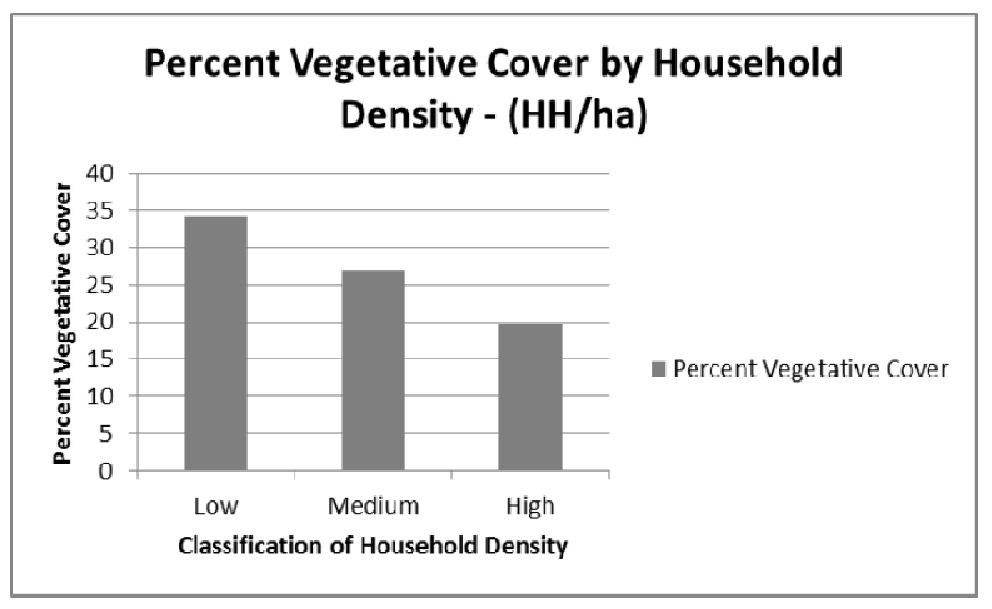

(b)

Figure 10. Vegetative cover relative to sectors' connectivity to the city water network. (a) Percent vegetated by sector infrastructure connectivity $(\mathrm{N}=34) ; \mathrm{R}^{2}=0.051$; (b) Percent vegetated in sectors of low, medium and high infrastructure connectivity $(\mathrm{N}=34)$.

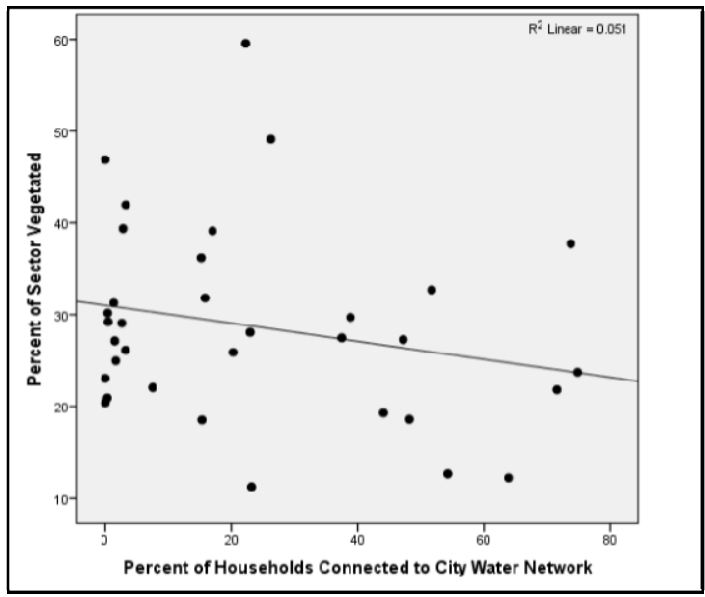

(a)

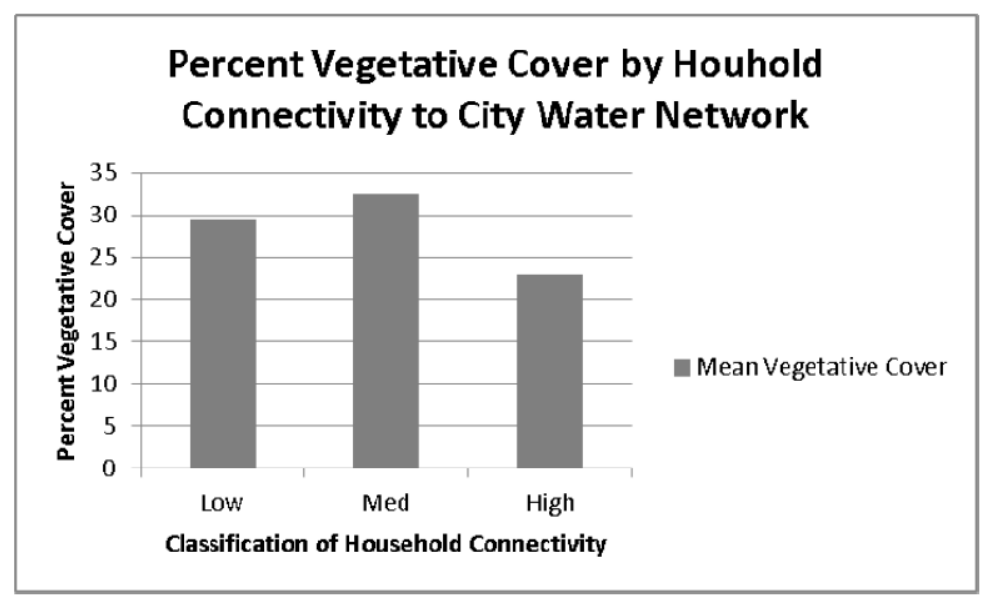

(b) 
Figure 11. Vegetative cover relative to sectors' housing tenure, or percentage of households owning (a) and renting (b). (a) Percent vegetated area by percent household owning in sectors $(\mathrm{N}=34) ; \mathrm{R}^{2}=0.207$; (b) Percent vegetated area by percent households renting in sectors $(\mathrm{N}=34) ; \mathrm{R}^{2}=0.296$.

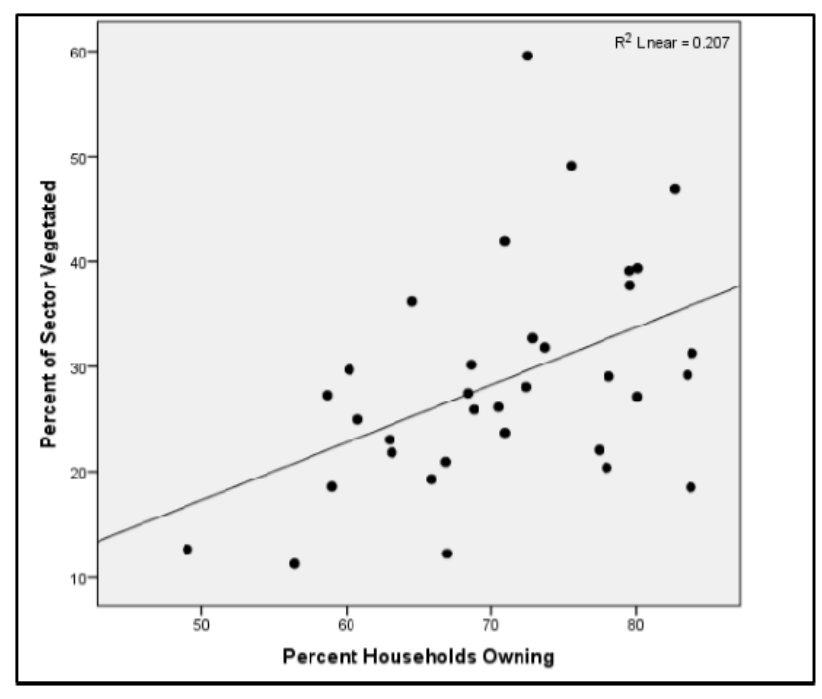

(a)

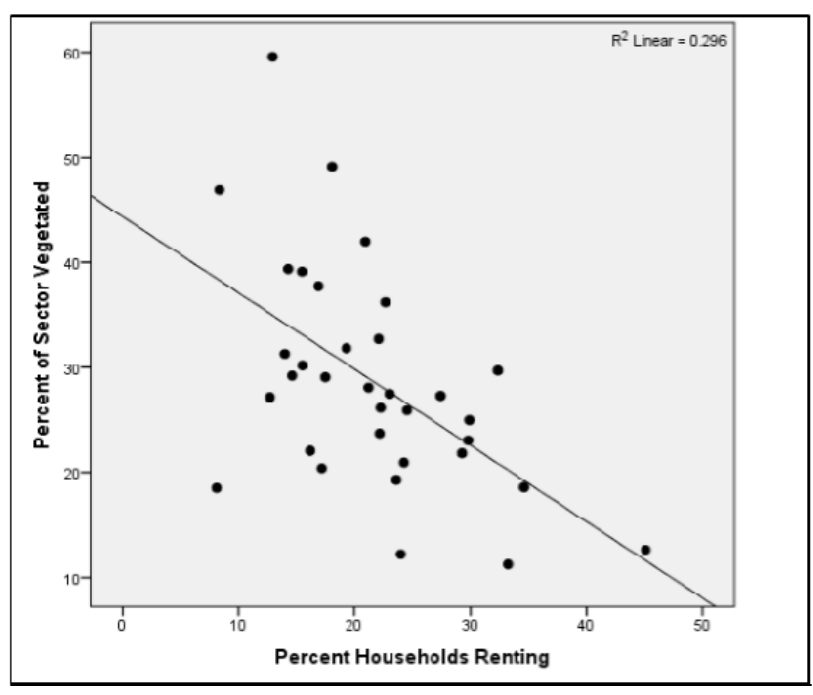

(b)

\subsection{Multivariate Regression Model}

To more systematically assess the relative importance and significance of each of these socioeconomic factors for explaining urban vegetation patterns in Altamira, we conducted a multivariate regression analysis with relative extent (percent) vegetative cover of a sector as the dependent variable, and a set of five independent variables representing household density, mean sector monthly household income, percent of households connected to city water system, percent of households owning, and percent of households renting and four additional dummy variables capturing sector urbanization phase. Table 3 notes the summary statistics for each variable in the model, and Table 4 notes regression results.

Table 3. Summary statistics for dependent and independent variables.

\begin{tabular}{cccc}
\hline Coefficients & Mean (Std. Dev.) & Min & Max \\
\hline Pct vegetative cover & $28.7(10.5)$ & 11.2 & 59.6 \\
Households per ha & $22.3(9.2)$ & 5.6 & 38.5 \\
Mean HH Income in R\$ & $601.5(285)$ & 241 & 1236.3 \\
Pct Water Piped & $23.8(24.1)$ & 0 & 74.9 \\
Pct HH Owning & $70.8(8.7)$ & 49 & 83.9 \\
Pct HH renting & $21.6(7.8)$ & 8.1 & 45.1 \\
\hline
\end{tabular}


Table 4. Multivariate regression analysis. $(\mathrm{N}=34$, parameters $=6)$. Dependent variable: Percent of vegetation cover in census sector. Model Summary: $\mathrm{R}^{2}=0.735 ; \mathrm{F}=8.67$; $p<0.0005$.

\begin{tabular}{ccc}
\hline Coefficients & $\boldsymbol{\beta}$ & $\boldsymbol{p}$ \\
\hline Constant & 100.083 & 0.0007 \\
Households per ha & -0.794 & $<0.0005$ \\
Mean HH Income & -0.025 & 0.001 \\
Pct Water Piped & 0.117 & 0.042 \\
Pct HH Owning & -0.414 & 0.294 \\
Pct HH renting & -0.614 & 0.168 \\
Urb Phase 1 ( $\leq 1970)$ & -2.117 & 0.517 \\
Urb Phase 3 (1985-1991) & 7.85 & 0.047 \\
Urb Phase 4 (1991-1996) & 9.066 & 0.081 \\
Urb Phase 2 (1970-1985) & Excluded Variable \\
\hline
\end{tabular}

\section{Discussion}

As anticipated, household density is significantly and inversely related to vegetative cover in Altamira, supported expectations that increases in population density likely drive reductions in urban vegetation cover. This result is not surprising as the process of creating new neighborhoods in Altamira, as in other cities of the Amazon, involves reduction in lot size, paving of surrounding surface to cope with soil saturation during the rainy season, and construction of permanent infrastructures. The latter includes streets and roads, parking lots, markets and institutional structures, which displace vegetation. This process seen in Altamira corresponds to other findings investigating the relationship between population density and urban vegetative cover.

Results of the analysis relating vegetative cover and income in Altamira are intriguing as they differ from findings from previous literature exploring patterns and drivers of urban vegetation. Pedlowski et al. [50] found that wealthier neighborhoods in Campos dos Goytacazes, Rio de Janeiro State, Brazil had both higher numbers and diversity of trees than poorer neighborhoods. They also found neighborhood age was not a significant factor of tree cover while socioeconomic levels seemed to play a causal role in tree abundance and species diversity. Our analyses also contradict other urban vegetation studies, particularly those that investigate the role of income in explaining extant vegetation patterns. For instance, Logan and Molotch [48] and Heynen [11] demonstrated that within American cities, high incomes are often associated with relatively high levels of urban tree canopy and vegetative cover. In contrast, we find a negative income-vegetation relationship, as census sectors with relatively high mean monthly incomes have lower percent vegetative cover.

This finding is consistent with our field experiences in Altamira over four decades, where we have observed that many wealthier households are located in areas of relatively high amounts of impervious surface cover in the urban cores, while "poorer" residents reside away from the most built up areas of the city in areas of lower household density and lower ratios of impervious surface to vegetative cover. Higher income areas in Altamira also have more urban amenities such as paving and sidewalks, which contribute to impervious surfaces in the city. Housing lots in these higher income areas also have a larger share of built up infrastructure in their front and back yards, relative to lots in less affluent 
neighborhoods. On the other hand, recently occupied urban areas typically have poor public infrastructure and housing. In this region of marked seasonality of rainfall, and frequently heavy rains, urban drainage and muddy lots are major concerns for residents. As such, impervious surfaces on a lot are considered an improvement and an indicator of status, further explaining correlation of affluent sectors with such surfaces.

Our results indicate that census sectors with high percentages of home ownership tend to have high vegetative cover. Conversely, sectors with high percentages of households renting tend to have lower vegetative cover. This likely occurs because renters tend to be found in the more densely populated areas of the city as many apartments above businesses are rented while homes owned tend to be found further from the city market centers in areas of lower household density. These findings are not statistically significant, however, suggesting that when other demographic, socioeconomic and urban development (e.g., time since urbanization) factors are controlled for, housing ownership tenure as captured in the percent owning or renting in a sector does not correlate significantly with urban vegetation in Altamira.

To meet calls for inclusion of a temporal component in urban vegetation research [12], we investigated the relationship between age of initial urbanization (urbanization phase) and vegetative cover. The dummy variable for Phase 2 was dropped from the model to avoid collinearity. We find that phase 3 and 4 (more recently urbanized sectors) are significantly likely to be associated with greater proportional vegetative cover. Conversely, the earlier that a sector had been urbanized, the lower its vegetative cover in 2008, on average. The significance of urbanization phase (i.e., time since urbanization) for vegetative outcomes in Altamira is congruent with other studies in which age of housing is found to be significantly associated with plant species composition [62], diversity [63] and abundance [64]. However, the nature of the relationship between urbanization phase and vegetation in the case of Altamira contradicts previous findings from other sites, since vegetative cover in Altamira is inversely related to age of census sector, whereas in the earlier studies cited here, older neighborhoods are associated with increased vegetative cover. In part, our divergent results may be due to the fact that Altamira is a much younger city compared with many others reported in the urban vegetation literature. As Altamira continues to develop in the future, it will be important to reexamine the evolution of its vegetative cover in neighborhoods of distinct ages.

These model findings reflect the nature of Altamira as a city and the related processes of agrarian frontier expansion and contraction in the Amazon, which has experienced significant growth since 1970. Costa and Brondizio [65] describe a common process of Amazonian urbanization in which urban expansion is largely unplanned with the first priority being the clearing of vegetation for semi-permanent shelters without the provision of other infrastructure. With interim housing established, individual priorities shift to developing higher quality dwellings using durable material, with secondary priorities of improving quality of access, as the rainy season in the LBA can be highly problematic in terms of maintaining access within areas of early development. With time, shelter and access requirements are met through permanent structures and improved, often paved, roads and priorities shift to other basic infrastructure improvements such as constructing and providing permanent access to networks of electricity, piped water and sewage disposal systems. Urban vegetation is low on the priority list of early urban development and limited later when much of the area is occupied and housing density has increased. Lot size allowing, many families invest in 
homegardens used to cultivate fruit trees and herbs. However, as higher priorities are adequately met, public investments in street trees and parks and private investments in home gardens [51], for aesthetic and recreational use along with benefits associated with eco-system services, may rise.

Additionally, Altamira does not reflect the high levels of social stratification perhaps experienced by other urban vegetation study sites in which various measures of social stratification were found to be significant predictors of vegetative cover. While there are considerable differences in mean income between census sectors in Altamira, the relative differences are small as compared to larger cities. This relatively muted income/social stratification prevalent today may change as the region continues on its trajectory of urban development.

\section{Conclusions}

Cities worldwide are the locations of dramatic transformation in land use, cover and ecological conditions. They also vary widely in terms of their size, political-economic contexts, urban history and development trajectories, and environmental settings. Such wide disparities make it difficult to extrapolate research findings from individual case studies such as the one presented here, to the global context. However, Altamira is a particularly telling and representative example in terms of the Amazon and other urbanizing forest frontier areas in Latin America. This area is emblematic of the development literature of the Amazon: socially and economically diverse, expanding at moderate to fast rate since the 1970s, and an important center for the future development of infrastructure and hydrolectrical dams.

This research project set out to explore three main questions related to the spatial distribution of urban vegetation in Altamira, its trajectories of urban expansion, and the key social indicators associated with its vegetation distribution. To answer these questions we employed remote sensing, GIS and statistical methods. The spatial distribution of urban vegetation was determined using a highly accurate segmentation based classification of a 2008 QuickBird image over Altamira. In addition, the role of urban expansion over time in determining vegetation patterns was explored through the analysis of time series remotely sensed datasets. Additional socioeconomic indicators provided by the 2000 Brazilian census were selected based on their emphasis in prior urban vegetation studies and their theorized influence on vegetation cover in Altamira.

In exploring the relationships between urban vegetative cover and socioeconomic and demographic variables in Altamira, this research finds that mean household income, time since initial urbanization and household density are all inversely related to vegetative cover, while the proxy measure of infrastructure development, percent of households connected to the city water system, is positively related to vegetative cover. Measures of tenure in the form of percent households owning and percent households renting are not significantly associated with percent vegetative cover at the scale of the census sector. Other tenure variables, such as length of household residency, not available at the time of analysis, should also be considered.

Our overall findings deviate partially from results of other studies investigating urban vegetation distributions in Brazil [50] and beyond [11]. Specifically, we find that neighborhoods (census sectors) with lower incomes had greater proportions of vegetative cover, contradicting studies of environmental justice that have linked environmental amenities such as tree cover to more affluent neighborhoods in 
cities. As well, we find that neighborhood age was a significant predictor of vegetation distribution, differing from studies elsewhere in Brazil [50] but echoing insights from other case studies in the urban north [12]. Such findings indicate that further studies in this region and in similar areas worldwide need to account for temporal urban trajectories as well as socioeconomic factors to explain spatiotemporal patterns of urban vegetative cover. Such vegetative patterns are likely to have important implications for ecosystem services and social benefits, and future research needs to integrate the social contexts with empirically derived measures of such benefits.

\section{Acknowledgments}

The purchase of QuickBird imagery was made possible with support from The National Institute of Child Health and Human Development at NIH (grant \# R01 HD035811). The study is part of a 5-year continuation project focusing on Population and Environment, which includes examining changes taking place in urban areas. Landsat imagery was acquired from the United States Geological Survey. Scott S. Hetrick would like to thank the Department of Geography at Indiana University, the Anthropological Center for Training and Research on Global Environmental Change, the Indiana Statistical Consulting Center, Dengsheng Lu and Anthony Cak. Any errors are solely the responsibility of the author and not of the funding agencies.

\section{Conflicts of Interest}

The authors declare no conflict of interest.

\section{References}

1. Vitousek, P.M.; Mooney, H.A.; Lubchenco, J.; Melillo, J. Human domination of Earth's ecosystem. Science 1997, 277, 494-499.

2. Grimm, N.B.; Grove, J.M.; Pickett, S.T.; Redman, C.L. Integrated approaches to long-term studies of urban ecological systems. BioScience 2000, 50, 571-584.

3. Lambin, E.F.; Turner, B.L.; Geist, H.J.; Agbola, S.B.; Angelsen, A.; Bruce, J.W.; Coomes, O.T.; Dirzo, R.; Fischer, G.; Folke, C. The causes of land-use and land-cover change: Moving beyond the myths. Glob. Environ. Chang. 2001, 11, 261-269.

4. Lambin, E.F.; Geist, H.J.; Lepers, E. Dynamics of land-use and land-cover change in tropical regions. Annu. Rev. Environ. Resour. 2003, 28, 205-241.

5. McGranahan, G.; Satterthwaite, D. Urban Centers: An assessment of sustainability. Annu. Rev. Environ. Resour. 2003, 28, 243-274.

6. Munroe, D.K.; Croissant, C.; York, A.M. Land use policy and landscape fragmentation in an urbanizing region: Assessing the impact of zoning. Appl. Geogr. 2005, 25, 121-141.

7. Urbanization and Global Environmental Change-IHDP. Available online: http://www.ihdp.unu.edu/ article/read/ugec-science-plan (accessed on 19 July 2013).

8. Grey, G.; Deneke, F. Urban Forestry; Wiley: New York, NY, USA, 1986.

9. Ulrich, R.S.; Simons, R.F.; Losito, B.D.; Fiorito, E.; Miles, M.A.; Zelson, M. Stress recovery during exposure to natural and urban environments. J. Environ. Psychol. 1991, 11, 201-230. 
10. Hill, K. Design and Planning as Healing Arts: The Broader Context of Health and Environment. In Ecology and Design: Frameworks for Learning; Johnson, B.R., Hill, K., Eds.; Island Press: Washington, DC, USA, 2002; Volume 1, pp. 203-214.

11. Heynen, N. The scalar production of injustice within the urban forest. Antipode 2003, 35, 980-998.

12. Grove, J.; Troy, A.; O’Neil-Dunne, J.; Burch, W.R.; Cadenasso, M.; Pickett, S.T.A. Characterization of households and its implications for the vegetation of urban ecosystems. Ecosystems 2006, 9, 578-597.

13. Heynen, N.; Perkins, H.A.; Roy, P. The political ecology of uneven urban green space: The impact of political economy on race and ethnicity in producing environmental inequality in Milwaukee. Urban Aff. Rev. 2006, 42, 3-25.

14. Simon, D.; McGregor, D.; Nsiah-Gyabaah, K. The changing urban-rural interface of African cities: Definitional issues and an application to Kumasi, Ghana. Environ. Urban 2004, 16, 235-247.

15. Aguilar, A.; Ward, P. Globalization, regional development, and megacity expansion in Latin America: Analyzing Mexico City's peri-urban hinterland. Cities 2003, 20, 3-21.

16. Mbiba, B.; Huchzermeyer, M. Contentious development: Peri-urban studies in Sub-Saharan Africa. Prog. Dev. Stud. 2002, 2, 113-131.

17. Jackson, L.E. The relationship of urban design to human health and condition. Landsc. Urban Plan. 2003, 64, 191-200.

18. Grossmann, W.D. Integration of Social and Ecological Factors: Dynamic Area Models of Subtle Human Influences on Ecosystems. In Humans and Components of Ecosystems: The Ecology of Subtle Human Effects and Populated Areas; McDonnell, M.J., Pickett, S.T.A., Eds.; Springer-Verlag: New York, NY, USA, 2003; pp. 229-245.

19. Tress, B.; Tress, G.; Decamps, H.; d'Hauteserre, A.-M. Bridging human and natural sciences in landscape research. Landsc. Urban Plan. 2001, 57, 137-141.

20. Madaleno, I. Urban agriculture in Belem, Brazil. Cities 2000, 17, 73-77.

21. Pauleit, S.; Duhme, F. Assessing the environmental performance of land cover types for urban planning. Landsc. Urban Plan. 2000, 52, 1-20.

22. Bolund, P.; Hunhammar, S. Ecosystem services in urban areas. Ecol. Econ. 1999, 29, 293-301.

23. Cities and the Environment; New Approaches to Eco-Cities; Inoguchi, T., Newman, E., Paoletti, G., Eds.; United Nations University Press: Tokyo, Japan/New York, NY, USA, 1999.

24. Roseland, M. Dimensions of the eco-city. Cities 1997, 14, 125-139.

25. Vliet, W.V. Cities in a globalizing world: From engines of growth to agents of change. Environ. Urban 2002, 14, 31-40.

26. United Nations Population Fund. Introduction and Chapter 1. The Promise of Urban Growth. In State of World Population 2007; Online Report; United Nations Population Fund. Available online: http://www.unfpa.org/swp/2007/english/introduction.html (accessed on 26 April 2013).

27. Urban Population-Data-Table. Available online: http://data.worldbank.org/indicator/ SP.URB.TOTL (accessed on 28 August 2013).

28. Panel on Urban Population Dynamics; Montgomery, M.R.; Stren, R.; Cohen, B.; Reed, H.E. Cities Transformed: Demographic Change and Its Implications in the Developing World; National Academy Press: Washington, DC, USA, 2003. 
29. United Nations Centre for Human Settlements (Habitat) (UNCHS-Habitat). The State of the World Cities Report 2001; UN-Habitat: New York, NY, USA, 2001.

30. Land, Rights and Innovation: Improving Tenure Security for the Urban Poor; Payne, G., Ed.; ITDG Publishing: London, UK, 2002.

31. Rakodi, C. Economic Development, Urbanization and Poverty. In Urban Livelihoods. A People-Centered Approach to Reducing Poverty; Rakodi, C., Lloyd-Jones, T., Eds.; Earthscan: London, UK, 2002.

32. World Bank. Poverty Reduction and the World Bank: Progress in Fiscal 2000 and 2001; World Bank: Washington, DC, USA, 2001.

33. Nowak, D.J. Atmospheric carbon reduction by urban trees. J. Environ. Manag. 1993, 17, 275-269.

34. Oke, T.R. The micrometeorology of the urban forest. Philos. Trans. R. Soc. Lond. B 1989, 324, 335-349.

35. Nowak, D.J. Air Pollution Removal by Chicago's Urban Forest. In Chicago's Urban Forest Ecosystem: Results of the Chicago Urban Climate Project; McPherson, E.G., Nowak, D.J., Rowntree, R.A., Eds.; USDA GTR-NE-186; Northeastern Forest Experiment Station: Radnor, PA, USA, 1994; pp. 63-81.

36. Cook, D.I. Trees, Solid Barriers, and Combinations: Alternatives for Noise Control. In Proceedings of the National Urban Forestry Conference; Hopkins, G., Ed.; USDA Forest Service/College of Environmental Science and Forestry, The State University of New York: Syracuse, NY, USA, 1978; pp. 330-339.

37. Sanders, R.A. Urban vegetation impacts on the hydrology of Dayton, Ohio. Urban Ecol. 1986, 9 , 361-376.

38. Breuste, J.; Feldmann, H.; Uhlmann, O. Urban Ecology; Springer-Verlag: Berlin, Germany, 1998.

39. Hough, M. City Form and Natural Process; Routledge: London, UK, 1989.

40. Randolph, J. Environmental Land Use and Management; Island Press: Washington, DC, USA, 2004.

41. Kuo, F.E.; Bacaicoa, M.; Sullivan, W.C. Transforming inner-city landscapes trees, sense of safety, and preference. Environ. Behav. 1998, 30, 29-59.

42. Sullivan, W.C.; Kuo, F.E. Do Trees Strengthen Urban Communities, Reduce Domestic Violence? In Urban and Community Forestry Assistance Program Technology Bulletin No. 4; US Department of Agriculture, Forest Service: Southern Region, Atlanta, GA, USA, 1996.

43. Ulrich, R. View through a window may influence recovery from surgery. Science 1984, 224, 420-421.

44. Wells, N.M. At home with nature: Effects of "greenness" on children's cognitive functioning. Environ. Behav. 2000, 32, 775-795.

45. Schroeder, H.W. Preference and meaning of arboretum landscapes: Combining quantitative and qualitative data. J. Environ. Psychol. 1989, 11, 231-248.

46. Kweon, B.S.; Sullivan, W.C.; Wiley, A.R. Green common spaces and the social integration of inner-city older adults. Environ. Behav. 1998, 30, 832-858. 
47. Agarwal, C.; Green, G.M.; Grove, J.M.; Evans, T.; Schweik, C.M. A Review and Assessment of Land-Use Change Models. Dynamics of Space, Time, and Human Choice; Gen. Tech. Rep. NE-297; US Department of Agriculture, Forest Service, Northeastern Research Station: Newtown Square, PA, USA, 2002; p. 61. Available online: http://www.nrs.fs.fed.us/pubs/gtr/gtr_ne297.pdf (accessed on 28 August 2013)

48. Logan, J.R.; Molotch, H.L. Urban Fortunes: The Political Economy of Place; University of California Press: Los Angeles, CA, USA, 1987.

49. Heynen, N. Green urban political ecologies: Toward a better understanding of inner-city environmental change. Environ. Plan. A 2006, 38, 499-516.

50. Pedlowski, M.A.; Da Silva, V.A.C.; Adell, J.J.C.; Heynen, N.C. Urban forest and environmental inequality in Campos dos Goytacazes, Rio de Janeiro, Brazil. Urban Ecosyst. 2002, 6, 9-20.

51. WinklerPrins, A.M.G.A. House-lot gardens in Santarém, Pará, Brazil: Linking rural with urban. Urban Ecosyst. 2002, 6, 43-65.

52. Padoch, C.; Brondızio, E.; Costa, S.; Pinedo-Vasquez, M.; Sears, R.R.; Siqueira, A. Urban forest and rural cities: Multi-sited households, consumption patterns, and forest resources in Amazonia. Ecol. Soc. 2008, 13. Available online: http://www.ecologyandsociety.org/vol13/iss2/art2/ (accessed on 28 August 2013).

53. Guedes, G.; Costa, S.; Brondízio, E. Revisiting the hierarchy of urban areas in the Brazilian Amazon: A multilevel approach. Popul. Environ. 2009, 30, 159-192.

54. Moran, E.F. Developing the Amazon; Indiana University Press: Bloomington, IN, USA, 1981.

55. Instituto Brasileiro de Geografia e Estatística. Censo Demográfico 2000; Agregado de Setores Censitários dos Resultados do Universo. Documentação dos Arquivos de Dados; Instituto Brasileiro de Geografia e Estatística: Rio de Janeiro, Brazil, 2002.

56. Instituto Brasileiro de Geografia e Estatística. Censo Demográfico 2010; Resultados do Universo-Características da População e dos Domicílios. Available online: http://www.sidra.ibge.gov.br/bda/tabela/listabl.asp?c $=1378 \& \mathrm{z}=\mathrm{cd} \& \mathrm{o}=5 \quad$ (accessed $\quad$ on 28 August 2013).

57. IBGE-Cidades@-Pará-Altamira. Available online: http://www.ibge.gov.br/cidadesat/xtras/ perfil.php? codmun=150060\&search=para|altamira (accessed on 28 August 2013).

58. Moran, E. Field Notes at Altamira PA, Brazil; 2013; Unpublished Note.

59. ERDAS IMAGINE 2010 v10.1; Intergraph-Geospatial Operations: Norcross, GA, USA.

60. Lu, D.; Hetrick, S.; Moran, E. Land cover classification in a complex urban-rural landscape with QuickBird imagery. Photogramm. Eng. Remote. Sens. 2010, 76, 1159-1168.

61. Foody, G.M. Status of land cover classification accuracy assessment. Remote Sens. Environ. 2002, 80, 185-201.

62. Whitney, G.; Adams, D. Man as a maker of new plant communities. J. Appl. Ecol. 1980, 17, 431-448.

63. Hope, D.; Gries, C.; Zhu, W.; Fagan, W.F.; Redman, C.L.; Grimm, N.B.; Nelson, A.L.; Martin, C.; Kinzig, A. Socioeconomics drive urban plant diversity. Proc. Natl. Acad. Sci. USA 2003, 100, 8788-8792.

64. Martin, C.A.; Warren, P.S.; Kinzig, A.P. Neighborhood socioeconomic status is a useful predictor of perennial landscape vegetation in small parks surrounding residential neighborhoods in Phoenix, Arizona. Landsc. Urban Plan. 2004, 69, 355-368. 
65. Costa, S.M.; Brondizio, E.S. Inter-urban dependency among Amazonian cities: Urban growth, infrastructure deficiencies, and socio-demographic networks. REDES 2009, 14, 211-234.

(C) 2013 by the authors; licensee MDPI, Basel, Switzerland. This article is an open access article distributed under the terms and conditions of the Creative Commons Attribution license (http://creativecommons.org/licenses/by/3.0/). 